\title{
SHAKING TABLE TESTS ON NARROW MECHANICALLY STABILIZED EARTH WALLS
}

\author{
Ahmed S. Rabei ${ }^{1}$, Rami El-Sherbiny ${ }^{2}$, Omar Ezzeldine ${ }^{2}$ and Mohamed I. Amer ${ }^{2}$ \\ ${ }^{1}$ Cairo University and Teaching Assistant, Scientific Research Developing Unit, Beni \\ Suef University, Egypt \\ ${ }^{2}$ Public Works Department, Cairo University, Egypt
}

\begin{abstract}
Recently, the construction of Narrow Mechanically Stabilized Earth (NMSE) Walls of aspect ratio (ratio of reinforcement length, L, to wall height, H) below 0.7 is needed in developing urban areas. NMSE walls are subjected to seismic ground excitation when constructed in active seismically areas. This investigation focuses on the behavior of rigid NMSE walls based on reduced-scale shaking table tests. This involves performing three small 1-dimensional shaking table tests, $1 / 8$ of the prototype model. The models are excited using stepped amplitude sinusoidal base accelerations with incrementally increasing displacement amplitude and constant frequencies to generate an equivalent base acceleration ranging from $0.05 \mathrm{~g}$ to $0.7 \mathrm{~g}$ or until failure. The models have an aspect ratio, $\mathrm{L} / \mathrm{H}, 0.4$ and the ground motions predominant frequencies are assumed to be $1,2.5$ and $5 \mathrm{~Hz}$. The results show shat increasing the predominant frequency from 1 to $5 \mathrm{~Hz}$ reduces the critical accelerations from $0.4 \mathrm{~g}$ to $0.2 \mathrm{~g}$, respectively. Also, the results show that the critical acceleration is highly sensitive to the input motion predominant frequency. Consequently, the maximum design acceleration proposed by pseudostatic design method $(0.3 \mathrm{~g})$ isn't agreement with this study.
\end{abstract}

\section{Keywords: Shaking Table, NMSE Walls, Rigid Face, frequency, Amplification Factor}

\section{INTRODUCTION}

As stated by Morrison et al. (2006) it is necessary for sites that have limited spaces, steep terrain and rights-of-way to overcome the geometric constraints of mechanically stabilized earth (MSE) walls. Subsequently, the construction of narrow mechanically-stabilized earth (NMSE) walls in limited spaces and/or in-front of stabilized face are gaining popularity as a technique to expand the width of embankments and roadways on slopes that are already stable. NMSE walls are defined here, typically, the walls that have $\mathrm{L} / \mathrm{H}$ less than 0.70 and constructed in front of an existing stabilized face of shoring wall as stated in Morrison et al. (2006)-FHWA-CFL/TD-06-001. The traditional MSE walls reinforced by geosynthetics sheets have been examined by conducted a series of small scale shaking table tests. Bathurst and Alfaro (1996), Matsu et al. (1998), Bathurst et al. (1996), and El-Emam and Bathurst (2004) reported the results of these models.

Various shaking table tests were conducted on MSE walls and reported in the literature before 2002, but none of these studies involved MSE walls with $\mathrm{L} / \mathrm{H}<0.7$. Shaking table tests on $0.5-0.53 \mathrm{~m}$ high propped-panel models with phosphor-bronze reinforcement strips showed that permanent horizontal displacements of these walls were lower than the permanent displacements of the conventional walls (Watanbe et al. 2003). The presence of longer reinforcement at the top decreased the permanent displacements, and the tensile stresses in this extended layer were measured to be larger. Overturning was observed to be the main failure mode. Bathurst et al. (2002) evaluated the effects of facing batter and the interface shear properties of facing by testing four different 1:6 scale 1-m-high reinforced segmental retaining wall models on the shaking table using a base input frequency of $5 \mathrm{~Hz}$, corresponding to the $2 \mathrm{~Hz}$ used in the prototype. The vertical wall with fixed block-block and block-geosynthetic interfaces had the smallest displacements. The vertical wall with frictional interfaces performed the worst, but increasing the wall batter improved performance. Acceleration amplification factors as high as 2.2 were recorded at 
the top. Geosynthetic tensile loads were low compared with capacity. The actual failure mechanism was difficult to predict.

El-Emam and Bathurst $(2004,2005$, and 2007) reported the results from shaking table tests on 1-m-high $1=6$ scale model GRS walls with rigid facing panels and poorly graded dry sand as backfill. Geogrids with stiffness of 90 or $1,250 \mathrm{kN} . \mathrm{m}$ (taken at $2 \%$ strain) were used. In accordance with the similitude rules by Iai, the stiffness of geogrids in the corresponding prototype walls was 36 times these values. A stepped amplitude sinusoidal function at a $5-\mathrm{Hz}$ predominant frequency was used as base excitation. A horizontally restrained toe attracted $40-60 \%$ of the peak total horizontal earth

Until now the data base in literature comprises only full scale field test results (Morrison et al. (2006), the results of the twenty two centrifuge models that stated by Woodruff (2003) and finite element analysis that stated by Yang et al. (2008). However, the results of this data don't provide comprehensive records about the NMSE wall stability specifically when they constructed in active seismically zones. Accordingly, a series of small scale shaking table tests are performed to quantitatively investigate the stability of NMSE walls under seismic excitation. NMSE wall defined as wall of aspect ratio (ratio of reinforcement length, $\mathrm{L}$, to wall height, $\mathrm{H})<0.7$

A first step in this research is construction of three 1/8-scale model NMSE walls with full-height rigid facing and tested in Cairo University Shake Table to capture the dynamic behavior of small-scale NMSE walls. The reduced-scale model is $1 / 8$ of the prototype wall and tested using synthetic motions. The tested walls were taken to failure using a ramped sinusoidal horizontal base acceleration records.

\section{SHAKING TABLE AND REINFORCED SOIL MODEL WALL}

\subsection{Shaking Table}

1 -g uni-axial shaking table is used in this study. The table steel platform has dimensions $1.5 \mathrm{~m}$ by $1.5 \mathrm{~m}$, maximum payload capacity 2 tons at frequencies up to $50 \mathrm{~Hz}$ and peak base acceleration amplitude up to $\pm 1 \mathrm{~g}$. A rigid steel square box of dimensions $1.1 \mathrm{~m}$ wide/length by $1.0 \mathrm{~m}$ height is bolted to the table and confined the models. The back side of the box is used to simulate the stabilized face. Also, sand papers are attached to the back of the box and the base to create an interface between the existing face and the foundation soil. $8 \mathrm{~mm}$-thick of transparent Plexiglas was used to cover the side wall of the strong box.

\subsection{NMSE model wall configurations and instrumentations}

Tests setup and models configuration are shown in Fig. 1 and summarized in Table 1. The instrumentation layout and cross section are described in details in Fig. 1a and 1b. The design of experimental program was selected to focus on the influence of the following parameters on rigid facing NMSE wall response during base shaking:

a) The predominant frequency of the input base acceleration.

b) The input base acceleration amplitude.

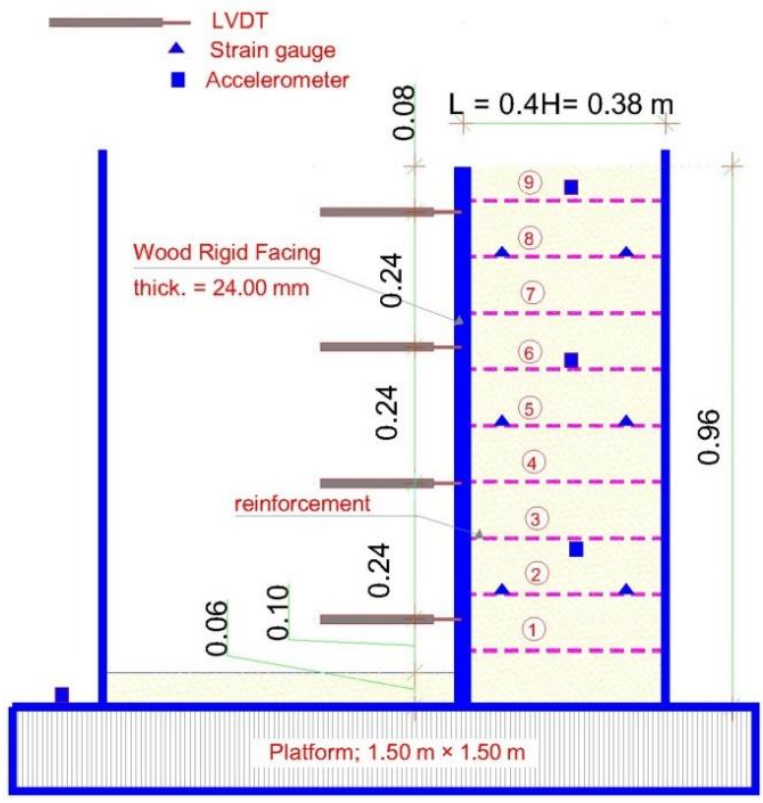

(a)

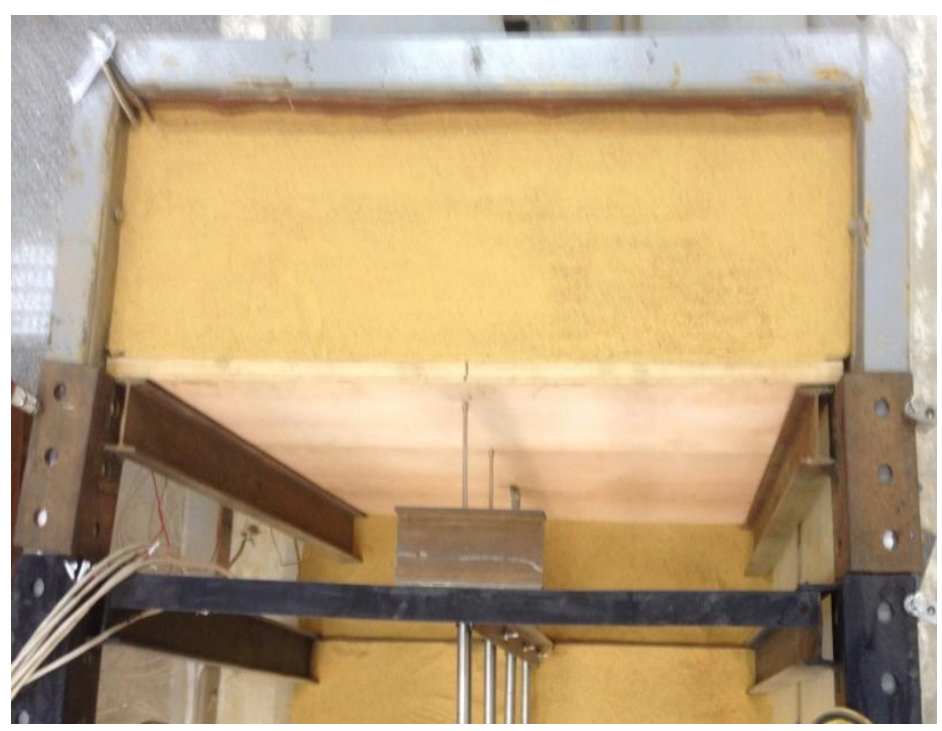

(b)

Fig. 1 Wall configurations and instrumentation layout of NMSE wall model (a) cross section (b) 3D view 
Table 1: Test configuration `and setup

\begin{tabular}{c|c|c|c|c}
\hline \multirow{2}{*}{$\begin{array}{c}\text { Test } \\
\text { no. }\end{array}$} & L/H & $\begin{array}{c}\text { Stiffness } \\
(\mathrm{kN} / \mathrm{m})\end{array}$ & $\begin{array}{c}\text { Vertical } \\
\text { spacing } \\
(\mathrm{mm})\end{array}$ & $\begin{array}{c}\text { Input motion } \\
\text { frequency } \\
(\mathrm{Hz})\end{array}$ \\
\hline 1 & 0.4 & 15 & 100 & 1 \\
\hline 2 & 0.4 & 15 & 100 & 2.5 \\
\hline 3 & 0.4 & 15 & 100 & 5 \\
\hline
\end{tabular}

The wall aspect ratio is assumed to be 0.4 and reinforcement vertical spacing, $\mathrm{S}_{\mathrm{v}}$, was taken $0.10 \mathrm{~m}$ in order to isolate the effect of reinforcement density on the dynamic response of the model walls. Full height rigid facing panel of wood is, also, used. The facing panel was constructed using 3 panels of counter wood of total thickness $24 \mathrm{~mm}$ as given in Fig. 1b and interlocking each to gather to perform a full height panel. Bracing system for full height facing panels was used for construction purposes and the fixation of lvdts. Furthermore, sand and reinforcement layers in $100 \mathrm{~mm}$ thick lifts were installed. The soil was placed in a loose condition and compacted to $82 \%$ relative density. Moreover, the geogrid layers at each lift were placed and fixed to the rigid face. At the end, the bracing system was removed and this condition simulates the static loading stage. The wall construction method can be considered to be a construction technique that falls between the field case of an incrementally constructed (un-braced) modular block wall and full-height braced rigid panel method.

\subsection{Soil}

The backfill material used in this study was obtained from Dahshour district, north of the Nile valley, Giza, Egypt. It is visually classified a silica sandy soil. Specific gravity of sand is 2.67 and the maximum and minimum void ratios are measured to be 0.77 and 0.59 , respectively. The soil is classified according to USCS as a uniformly graded sand with $1 \%$ fine content, coefficient of curvature, $\mathrm{C}_{\mathrm{c}}=2.74$ and coefficient of uniformity, $\mathrm{C}_{\mathrm{u}}=0.91$. The bulk density of the backfill was maintained $16.70 \mathrm{kN} / \mathrm{m}^{3}$ which corresponding to a relative density, $\mathrm{D}_{\mathrm{r}}=82 \%$ and zero moisture content. Tri-axial tests were performed and the material produced a peak friction angle $\phi_{\text {peak }}=41^{\circ}$.

\subsection{Reinforcement}

Table 2 highlights the properties of the reinforcement material used in the NMSE wall modes. It is a commercially bi-axial knitted polyester (PET) geogrid of green color which has relatively small tensile strength at $2 \%$ strain. Based upon the scaling law proposed by Iai (1989), the relationship between prototype-scale reinforcement stiffness $\left(\mathrm{J}_{\mathrm{P}}\right)$ and NMSE wall model scale stiffness $\left(\mathrm{J}_{\mathrm{m}}\right)$ can be calculated as $\mathrm{J}_{\mathrm{P}}=\mathrm{J}_{\mathrm{m}} \lambda^{2}$, where $1 / \lambda$ is the model scale and was taken $1 / 8$ in this study.

Table 2: Geogrid reinforcement properties

\begin{tabular}{l|l}
\hline Raw material & Polyester (PET) \\
\hline Coating material & Polymer (color green) \\
Mass/unit area $\left(\mathrm{gm} / \mathrm{m}^{2}\right)$ & 130 \\
Aperture size $(\mathrm{mm})$ & 3.5 \\
Machine and cross machine direction & \\
Wide-width strip tensile strength $(\mathrm{kN} / \mathrm{m})$ & 2 \\
At $2 \%$ strain $(\mathrm{MD})$ & 15 \\
Ultimate $(\mathrm{MD})$ & \\
\hline
\end{tabular}

\subsection{Base input accelerations and instrumentations}

During shaking, fourteen instruments were used in each model. Four lvdts are mounted at the facing elevation to measure the displacements during shaking. Each lvdt is attached to a rigid steel bracing system that is fixed with the box by c-clamps as shown in Fig. 1b. Hence, the datum for the recorded displacements is the shaking table platform. Furthermore, the local reinforcement strain was measured directly using foil-type strain gauges attached to the reinforcement in the shaking direction. A calibration factor was determined from in-isolation wide-width tensile strip tests to convert the local strains to global strain values and to directly correlate strain gauge readings to average tensile load in the reinforcement. Acceleration response during shaking was measured using accelerometers with a range from $1 \mathrm{~g}$ to $2 \mathrm{~g}$ and frequency response were ranged between $1 \mathrm{mv}$ to $5 \mathrm{v}$. three accelerometers were embedded in the soil model at elevations $0.3 \mathrm{~m}, 0.6 \mathrm{~m}$ and $0.9 \mathrm{~m}$ in addition to one accelerometer attached to the table platform to measure the input base acceleration as shown in Fig. 2. The attached and embedded accelerometers records will be, also, used to determine the vertical distribution of the input acceleration response through the height of the modeled wall. 
A stepped-amplitude-sinusoidal function as shown in Fig. 3 of a predominant frequency 1, $2.5 \mathrm{and} 5 \mathrm{~Hz}$ is used as input base acceleration. The amplitude is increased in $0.05 \mathrm{~g}$ increments every $5 \mathrm{sec}$ until excessive deformation occurred. This simple base excitation record is more aggressive than a typical earthquake record with the same predominant frequency and amplitude according to Bathurst and Hatami (1998) and Matsu et al. (1998). However, this input motion was developed in this form to ensure that all tests were shacked in the same controlled manner and to facilitate quantitative comparison among different tests configurations.

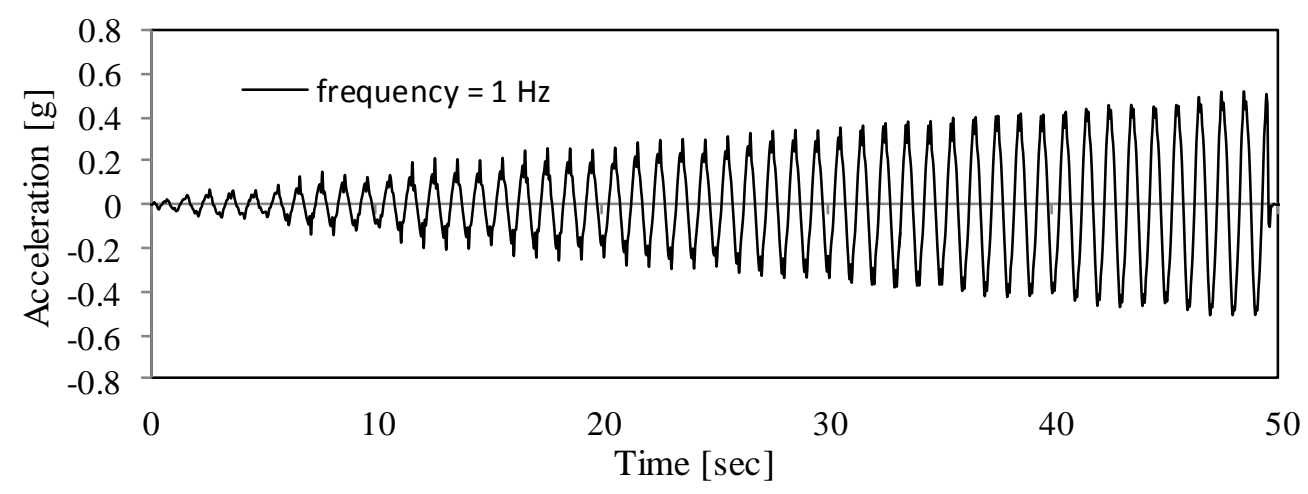

a) frequency $=1 \mathrm{~Hz}$

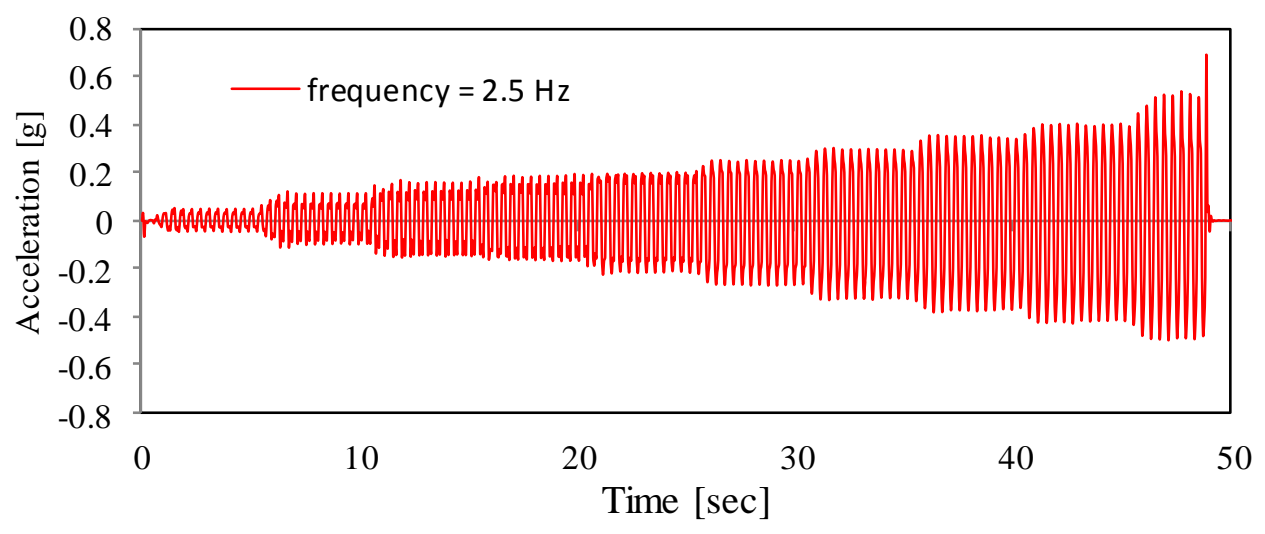

b) frequency $=2.5 \mathrm{~Hz}$

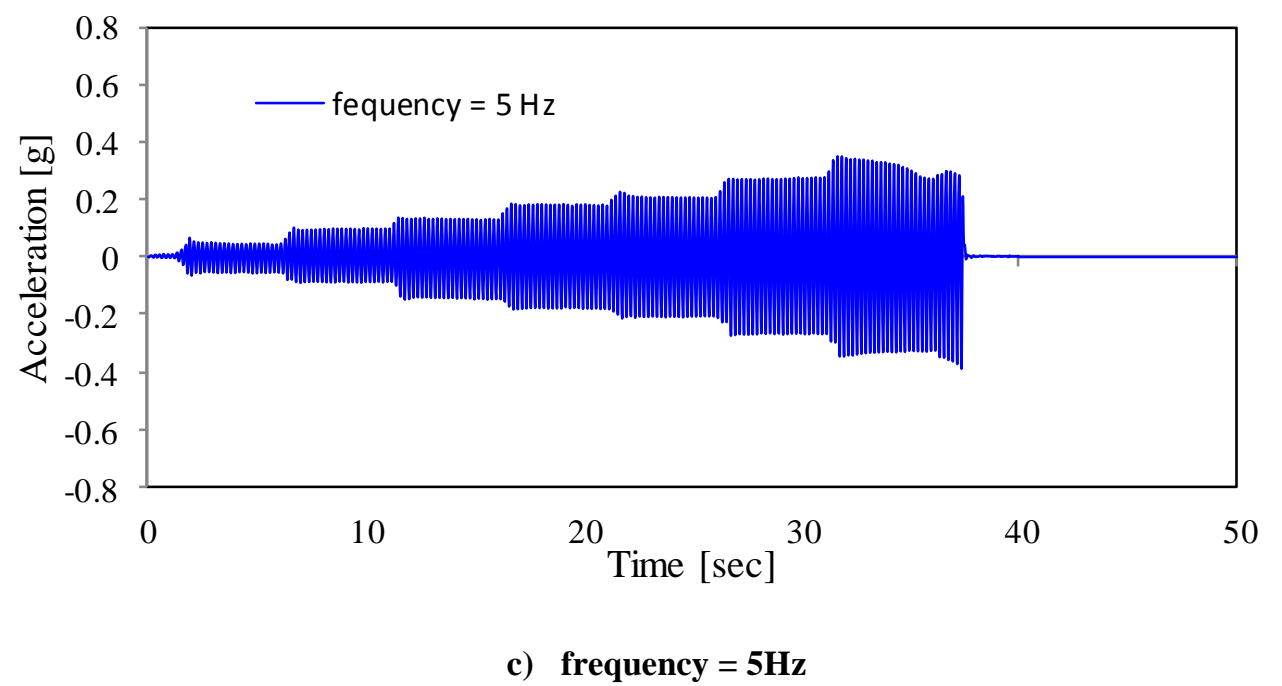

Fig. 2 Measured untreated input base acceleration.

\section{TYPICAL TEST RESULTS}

\subsection{General}

This section presents selected test results for test model number $1(\mathrm{~L} / \mathrm{H}=0.4$ and $1 \mathrm{~Hz}$ predominant frequency). The selected test results show wall facing displacement behavior with time, model wall acceleration response through the wall height and results of global strains resulted in reinforcement layers as shown in Fig. 3. 


\section{NMSE WALL FACING DISPLACEMENT}

Based upon the displacement-time histories of the tested models, the maximum top displacement at the average input peak acceleration for each increment are determined. Results in Fig. 4 show the effect of ground motion predominant frequencies and amplitude on wall deformations. The total displacement at any time was a combination of a recoverable dynamic deformation component and a permanent outward movement of the mean wall position. Similar deformation responses have been reported by Matsuo et al. (1998) and El-Emam and Bathurst (2004) for reinforced soil model wall assuming hinged full height rigid facing panel with $\mathrm{L} / \mathrm{H}>0.70$. Also, Watanabe et al. (2003) performed a series of shaking table tests considering the reduction of reinforcement length up to $0.4 \mathrm{H}$. The results are, also, very similar for the response of this research despite the displacement and the threshold acceleration values. Also, the results indicate that the magnitudes of deformations at any times were, clearly, dependent on the amplitude of the input base acceleration and shaking duration.

It is obvious from the results in Fig. 4 that the displacement amplitude are small for acceleration amplitudes less than $0.2 \mathrm{~g}, 0.32 \mathrm{~g}$ and $0.4 \mathrm{~g}$ for predominant frequencies $5 \mathrm{~Hz}, 2.5 \mathrm{~Hz}$ and $1 \mathrm{~Hz}$, respectively. However, the displacement amplitude and permanent deformations of the facing panel increased excessively when the peak base acceleration amplitude increased beyond these threshold acceleration values that reported previously. As stated by Bathurst and Alfaro (1996) and Bathurst et al. (2002) and Cai and Bathurst (1996), a threshold value can be used to identify a critical input base acceleration associated with wall failure in pseudo-static and displacement (sliding block) methods of analysis.

Although the displacement of wall facing at base acceleration less than the threshold values is small, the wall facing tends to rotate about toe with small toe deformations as shown in Fig. 5. Moreover, the overall predominant deformation mode is rotational as reinterpreted in Fig. 6. This result follows the same behavior as reported by El-Emam and Bathurst. (2004).

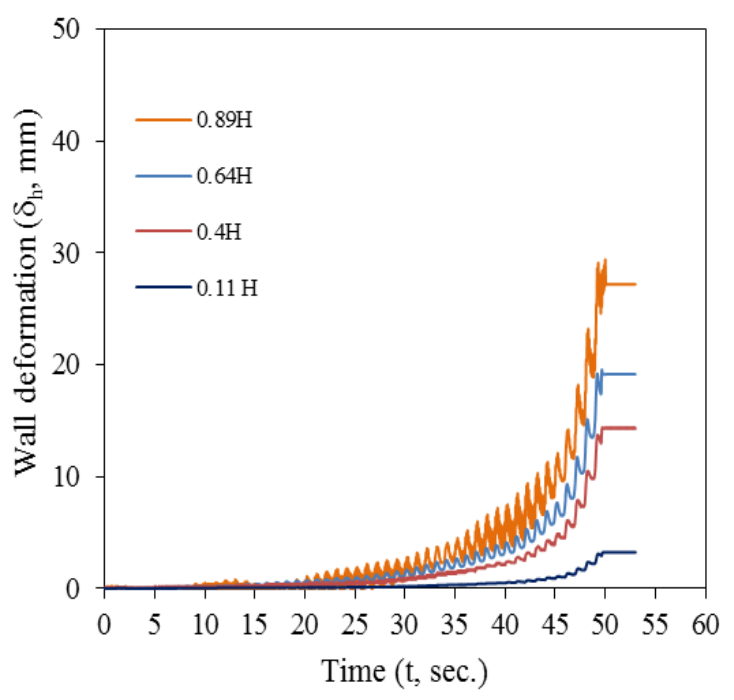

(a) Typical displacement-time history

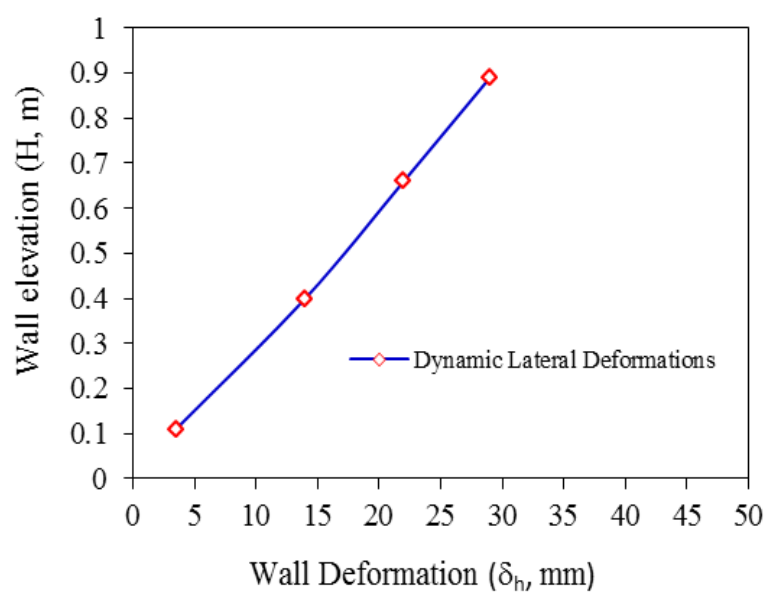

(c) Wall deformation at the end of shaking

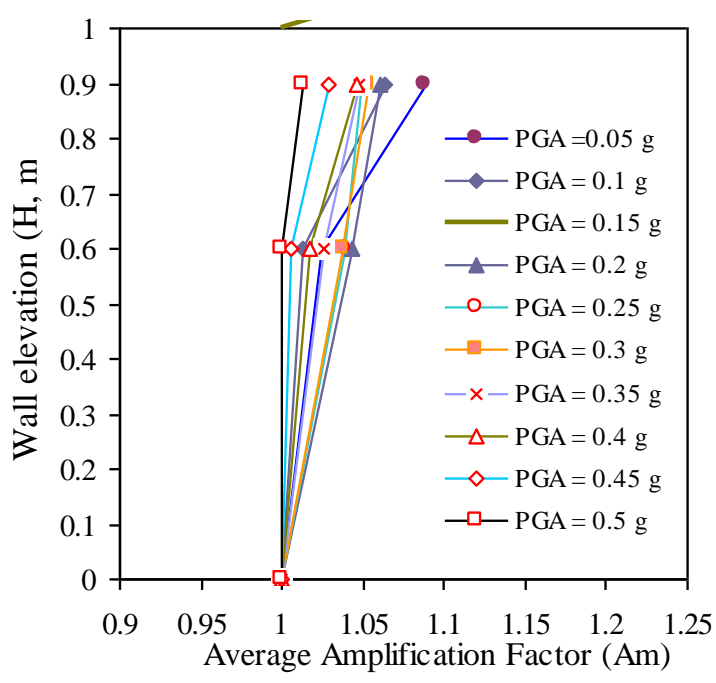

(b) Amplification factor profile

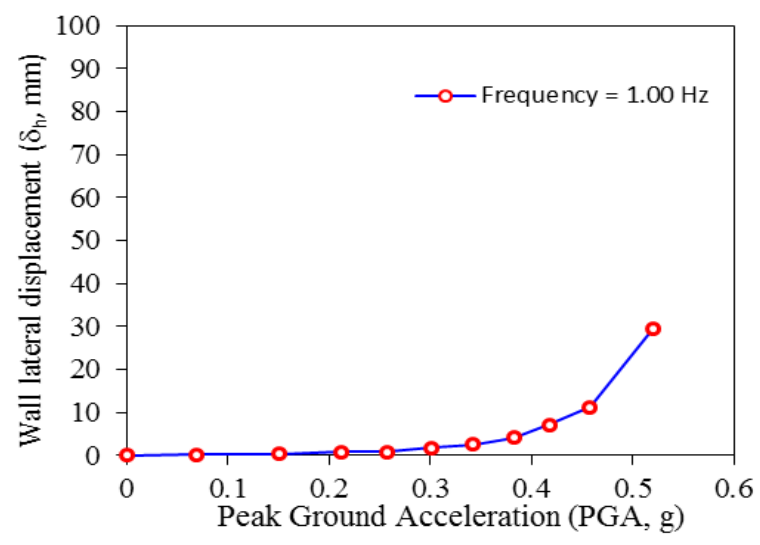

(d) Top wall deformations versus progression of input peak ground acceleration (PGA) 


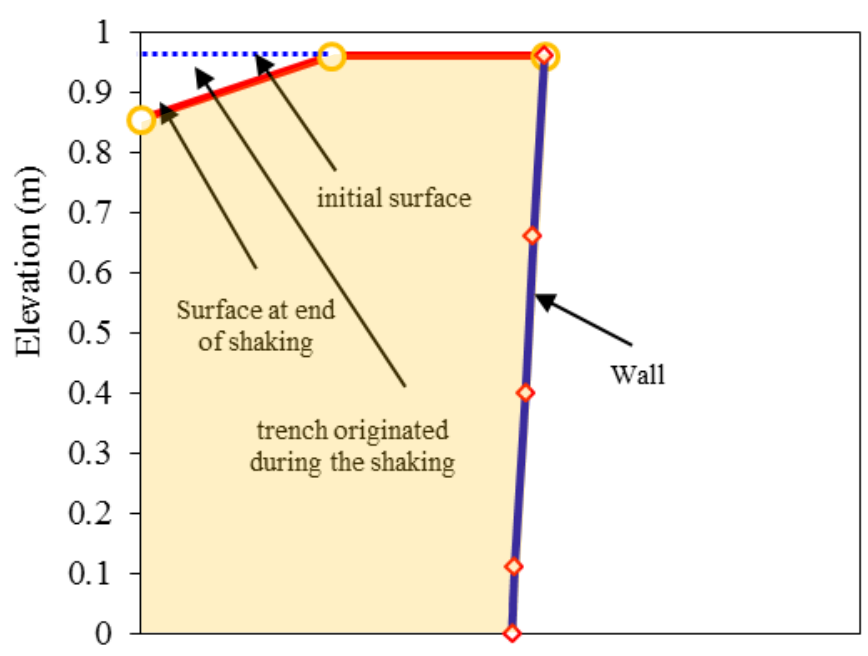

(e) Mass movement and surface subsidence

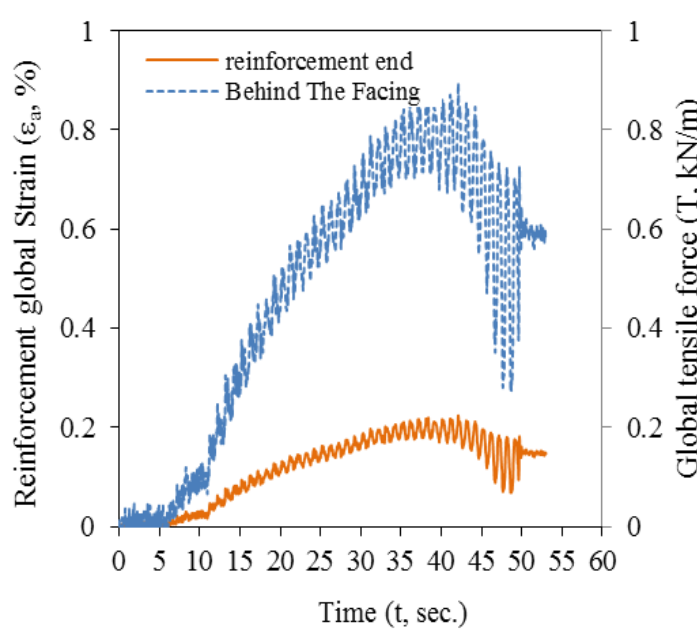

forcement global axial strain/load - time history (f) rein-

Fig. 3 Example model wall \# 1 results of $L / H=0.4$ and frequency $=1 \mathrm{~Hz}$.

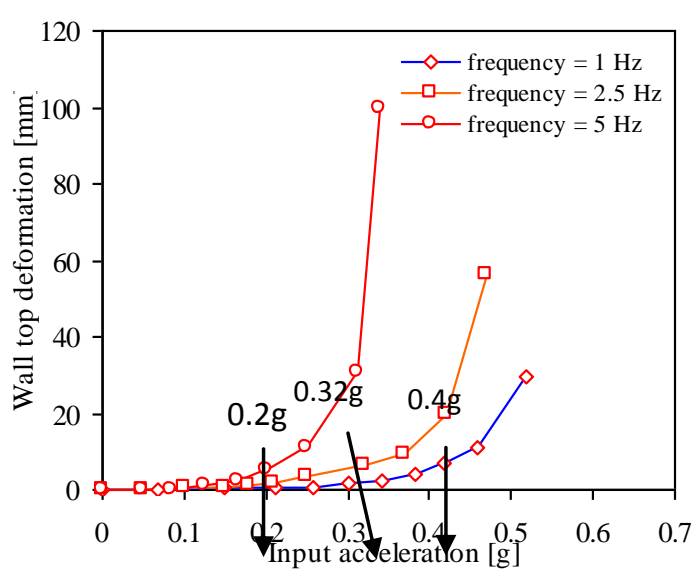

Fig. 4 Top wall displacement versus base acceleration at different frequencies

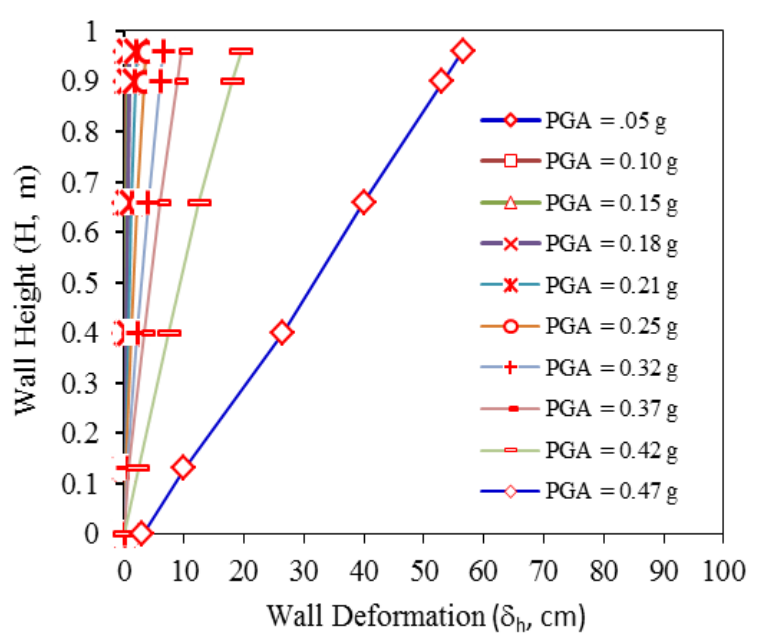

Fig. 5 Wall rotation versus progression of input peak ground acceleration (PGA)-wall no. 2

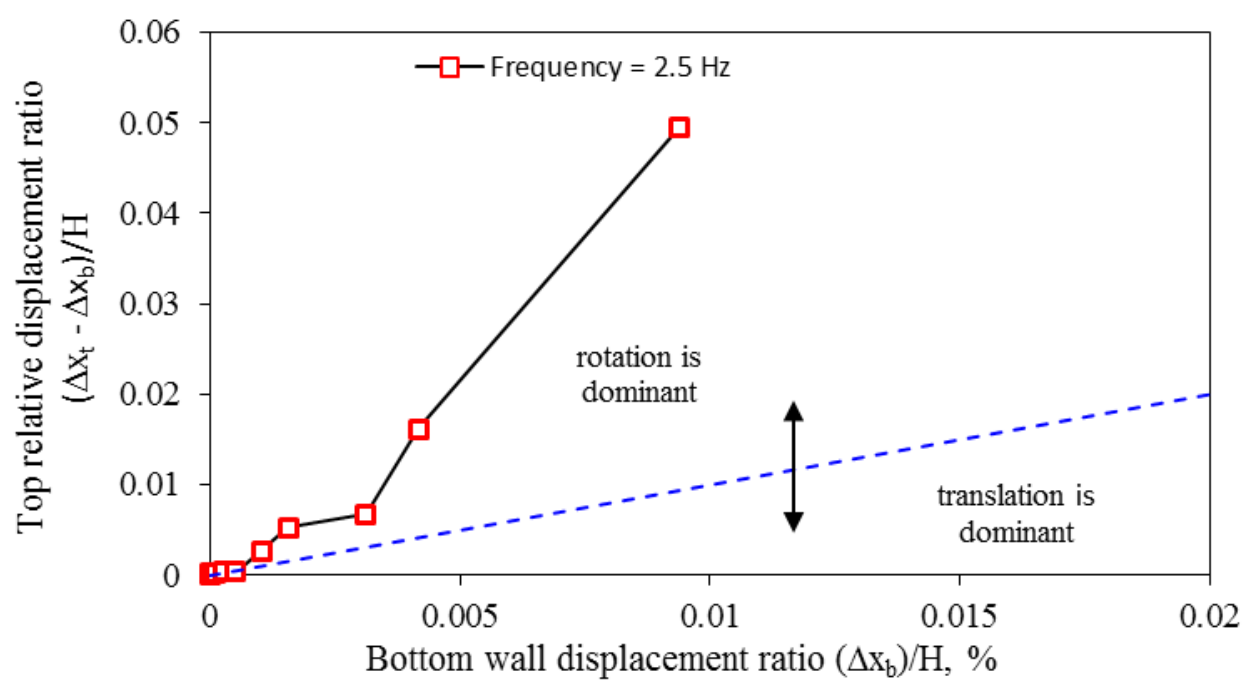

Fig. 6 Top relative displacement ratio versus bottom displacement ration Note: $\Delta \mathbf{x}_{b}=$ bottom displacement, $: \Delta \mathbf{x}_{t}=$ top displacement and $H=$ wall height 


\section{INPUT MOTION ACCELERATION AMPLIFICATION}

In this study, the distrbution of input base accelerations amplification through the centerline of rigid mass profile of NMSE wall is investigated. The effect of predominant frequencies of the input acceleration-time histories are, also, examined. Accordingly, the average of peak accelerations at each cycle is determined and divided by the input base accelerations and this is defined here as average amplification factro, Am. Figs. 7, 8 and 9 presents the average amplification factor profiles through the reduced model walls. Acceleration responses were measured at centerline of the reinforced soil mass at elevations $0.3,0.6$ and $0.9 \mathrm{~m}$.

Also, it was seen that increasing the frequency of input motions increases the amplification factor significantly up to 2.5. The increasing of the predominant frequency resulted in larger deformations at low critical accelerations due to the increasing number of cycles. This can be attributed to the larger deformations that occurred close to the critical acceleration and subsequently may lead to reduction in the wall stiffness. Also, the results highlight that the magnitude of amplification factor increases over the wall model height and is maximum at the surface. Similar response was reported by Bathurst and Hatami (1998). They explained that the confining pressure at the surface is very low and thus, the corresponding dynamic soil strain during shaking will be great.

The average amplification factor distribution at surface versus the peak input base acceleration is shown, also, in Fig. 10. The results show that the amplification factor increases with the peak input acceleration beyond $0.2 \mathrm{~g}$ to $0.25 \mathrm{~g}$ and reduced rabidly thereafter. This confirms the decoupling phenomenon that reported by Muir Wood 'et al. (2002). The phenomenon stated that the shorter walls respond to weak and moderately strong base accelerations (e.g. PGA<0.2g) with amplification factor higher than the strong sever base accelerations (e.g. PGA $=0.45 \mathrm{~g}$ ). They concluded that the higher shear stresses due to the strong base excitation results in decoupling of material within the backfill which reduces the soil capacity to transmit higher shear stresses to the surface and correspondingly lower acceleration amplification. The results of this phenomenon were, also, reported in previous researches (e.g.Siddharthan et al. (2004)).

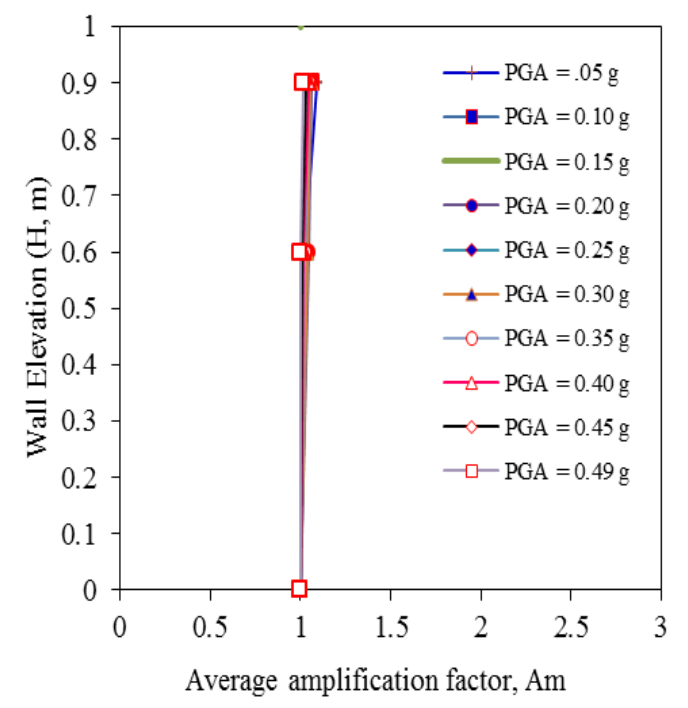

Fig. 7 Distrbution of vertical amplification factor for wall excited with $1 \mathrm{~Hz}$ frequency

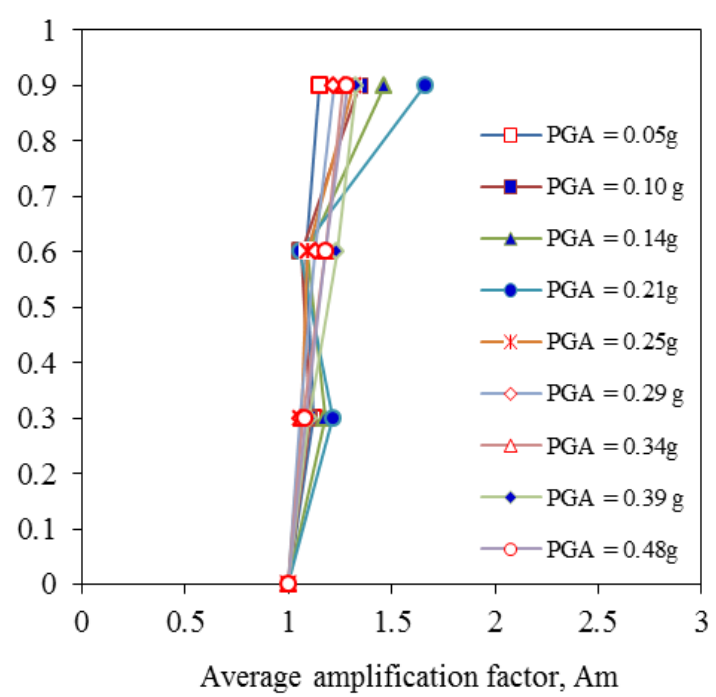

Fig. 8 Distrbution of vertical amplification factor for wall excited with $2.5 \mathrm{~Hz}$ frequency 


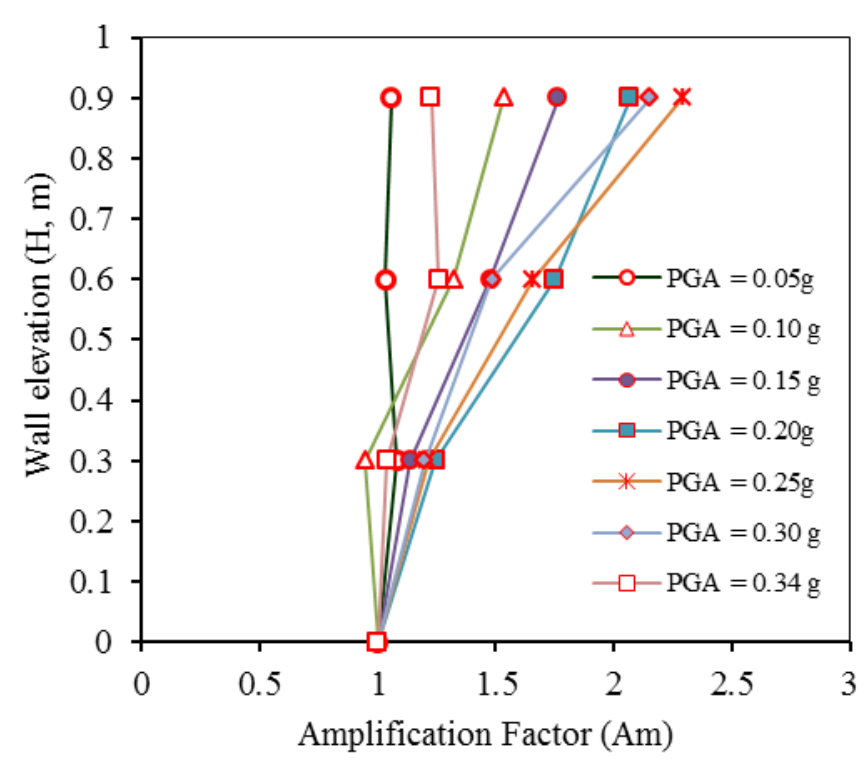

Fig. 9 Distrbution of vertical amplification factor for wall excited with $5.0 \mathrm{~Hz}$ frequency

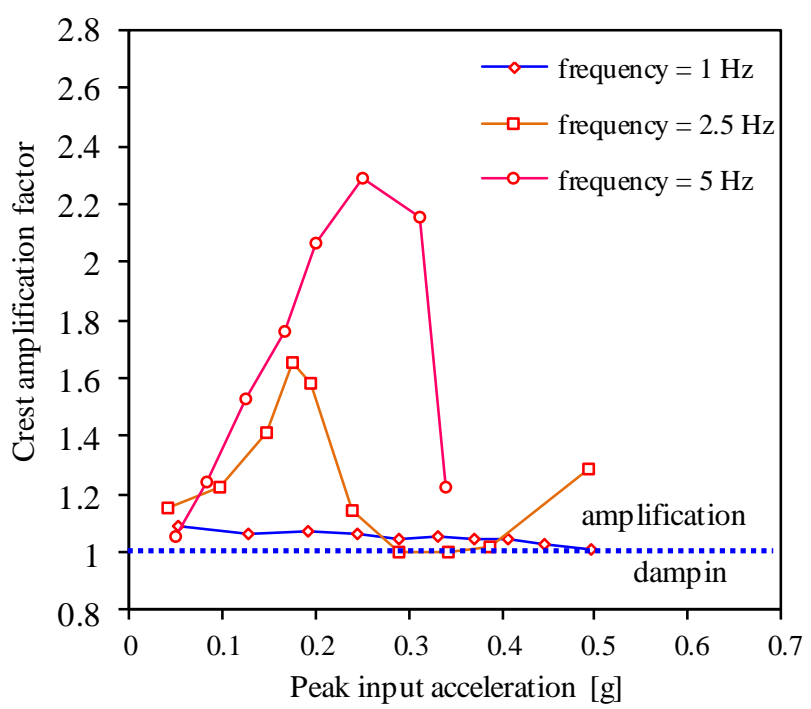

Fig. 10 Top amplification factor versus base acceleration at different frequencies of $\mathrm{L} / \mathrm{H}=0.4$

\section{REINFORCEMENT CONNECTION LOADS}

The reinforcement global strains are measured at layers no. 2, 5 and 8. Unfortunately, the strain distribution at each layer was difficult to be predicted because the limitations of strain module channels in the data acquisition system. The strain is measured only behind the facing and at the near end of reinforcement. The load was back-calculated from the measured strains using the load-strain relationship resulting from the wide-width strip tensile tests that performed on the reinforcement material used in this research as shown in Fig. 11. An example for reinforcement strain/tensile force-time history is shown, previously, in Fig. 3f. In this section, the vertical distribution of reinforcement loads behind the facing is shown. Figs. 12, 13 and 14 show the load reinforcement distribution versus wall elevation at input accelerations of frequency $1 \mathrm{~Hz}, 2.5 \mathrm{~Hz}$ and $5 \mathrm{~Hz}$, respectively. The results show that the lower reinforcement layer attracted loads higher than the upper reinforcement layers. This can be attributed to that the upper layers in the top half of the NMSE walls have a shortage of adequate soil confinement (i.e., lower overburden pressure). Furthermore, NMSE walls have reinforcement length smaller than the static design condition which makes the top half reinforcement layers became fully contained by the internal soil failure wedge as stated by El-Emam and Bathurst (2004).

The reinforcement connection loads were slightly affected by the predominant frequency of the input motions. It seems from the results that the excitation with lower dominant frequencies increases slightly the reinforcement connection loads for the bottom layer rather than the top layers. A possible explanation may be due to the smaller surface amplification factor corresponding to the lower dominant frequencies.

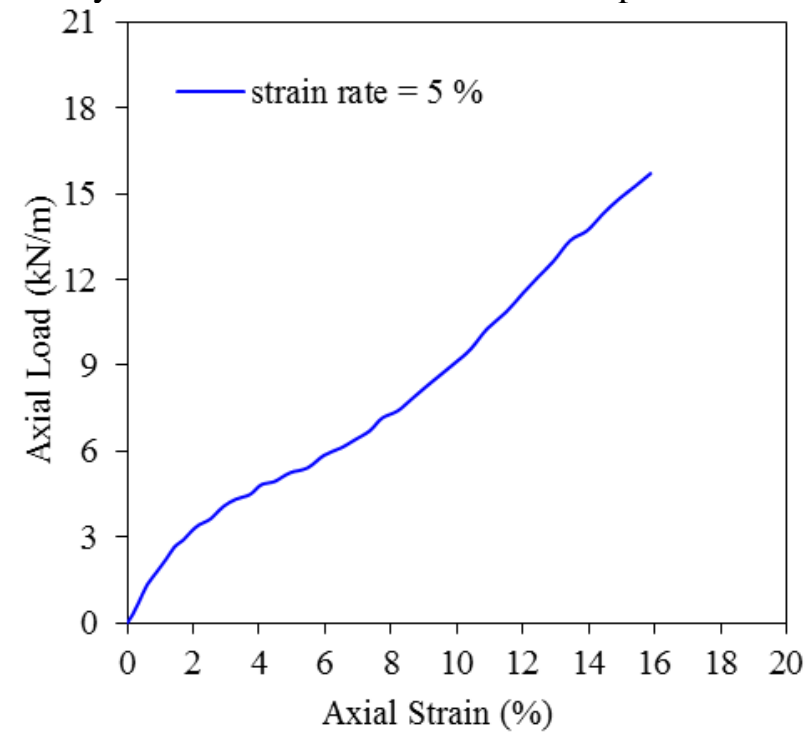

Fig. 11 Wide-width tensile test results for the reinforcement material

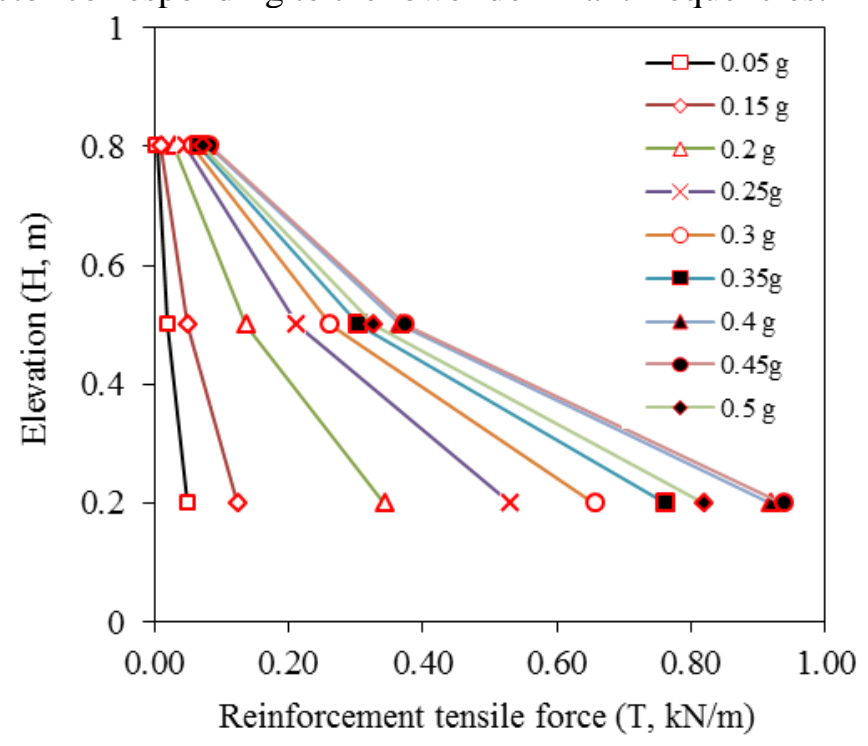

Fig. 12 Vertical distribution of reinforcement connection loads-wall no.1 


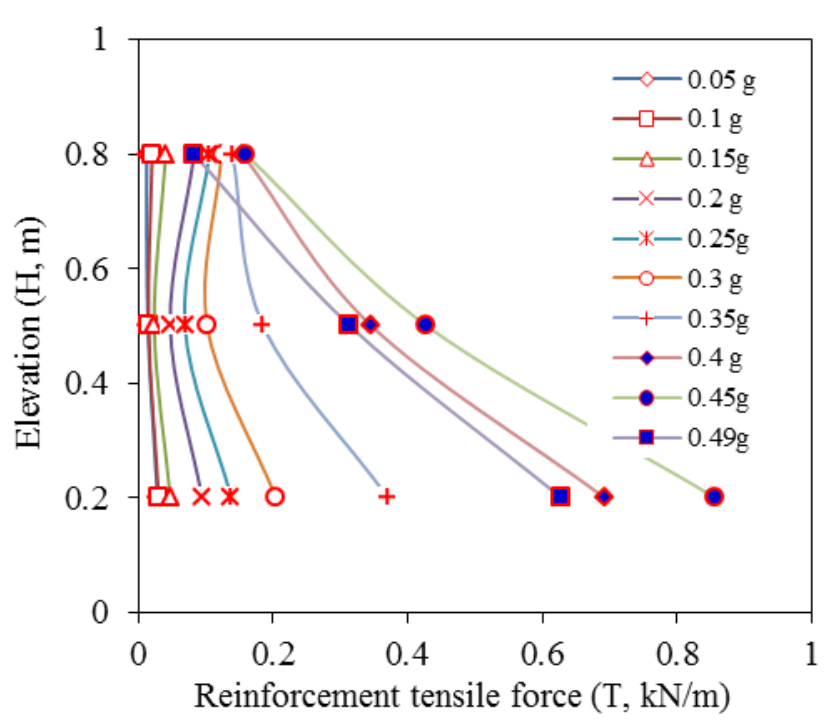

Fig. 13 Vertical distribution of reinforcement connection loads-wall no.2

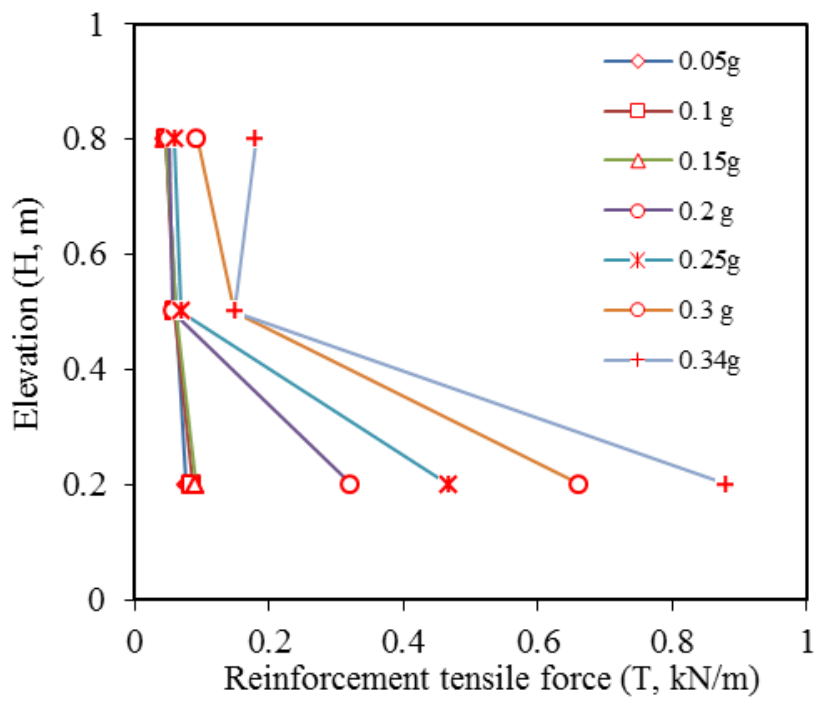

Fig. 14 Vertical distribution of reinforcement connection loads-wall no.3

\section{CONCLUSIONS}

This paper is a part of a long-term and comprehensive research which studies the seismic stability of NMSE walls constructed in limited spaces. The paper presents the results of series of three reduced scale shaking table tests that describe the response of full-height rigid facing walls considering the input base motion characteristics. Also, the paper introduces an introduction to the seismic behavior of NMSE walls under effect of multiple ground motions. The following conclusions are extracted from the results and analysis:

i. The lateral displacement magnitudes are, highly, dependent on the input base accelerations amplitudes. It was seen that the lateral permanent deformations increased with increasing the input acceleration amplitude.

ii. The maximum design accelerations are highly sensitive to the predominant frequency of the input base accelerations. Thus, the maximum design acceleration proposed by pseudo-static design method $(0.3 \mathrm{~g})$ isn't agreement with this investigation.

iii. The current design guidelines assume a maximum design value for the input base acceleration. This is a disagreement with this study. That is because 1.15 an average amplification factor for the input motion through the wall height is observed.

iv. The reinforcement connection loads are low sensitive to the input motion predominant frequency.

\section{REFERENCES}

1. Bathurst, R. J. \& Alfaro, M.C. 1996. Review of seismic design, analysis and performance of geosynthetic reinforced walls, slopes and embankments, Keynote paper. In: Ochiai, H., Yasufuku, N., Omine, K. (Eds.), Proceeding of the International Symposium on Earth Reinforcement. Fukuoka, Kyushu, Japan, 12-14 November 1996. vol. 2. Balkema, Rotterdam, pp. 887-918.

2. Bathurst, R. J. \& Cai, Z. 1994. In-isolation cyclic load-extension behaviour of two geogrids. Geosynthetics International, 1, Vol. 1, pp.3-17.

3. Bathurst, R. J. \& Hatami, K. 1998. Seismic response analysis of a geosynthetic-reinforced soil retaining wall. Geosynthetics International, 5, Vol. 1-2, pp. 127-166.

4. Bathurst, R. J. 1998. NCMA Segmental Retaining Wall Seismic Design ProcedureSupplement to Design Manual for Segmental Retaining Walls. National Concrete Masonry Association, Herndon, VA, USA, 187p.

5. Bathurst, R. J., Cai, Z. and Pelletier, M. J. 1996. Seismic design and performance of geosynthetic reinforced s mental retaining walls. Proceedings of the 10th Annual Symposium of the Vancouver Geotechnical Society, Vancouver, BC, Canada, 26 pp.

6. Bathurst, R. J., Hatami, K. and Alfaro, M.C., 2002. Geosynthetic-reinforced soil walls and slopes-seismic aspects. In: Shukla, S.K. (Ed.), Geosynthetics and their Applications. Thomas Telford Ltd., London, UK, pp. 327-392.

7. Cai, Z. \& Bathurst, R. J. 1996. Deterministic sliding block methods for estimating seismic displacements of earth structures. Soil Dynamics and Earthquake Engineering, 15, Vol. 4, pp. 255-268. 
8. El-Emam, M. \& Bathurst, R. J. 2004. Experimental design, instrumentation and interpretation of reinforced soil wall response using a shaking table. International Journal of Physical Modelling in Geotechnics, 4, Vol. 4, pp. 13-32.

9. Hartman, D., Ledezma, M., Xiao, M. and Zoghi, M. 2013. Shake table tests of MSE walls with tired derived aggregates (TDA) backfill. Proceedings of Geo-Congress, ASCE, San Diego, PP. 1168-1177.

10. Iai, S. 1989. Similitude for shaking table tests on soil-structure-fluid models in 1-g gravitational field. Soils and Foundations, Vol. 29, No. 1, pp. 105-118.

11. Matsuo, O., Tsutsumi, T., Yokoyama, K. and Saito, Y. 1998. Shaking table tests and analysis of geosynthetic-reinforced soil retaining walls. Geosynthetics International, Vol. 5, pp. 97126.

12. Morrison, K., Harrison, F., Collin, J., Dodds, A. and Arndt, B. 2006. Shored Mechanically Stabilized Earth (SMSE) Wall Systems. FHWA-CFL/TD-06-001. 212 pg.

13. Muir Wood, D., Crewe, A. and Taylor, C. 2002. Shaking table testing of geotechnical models. International Journal of Physical Modelling in Geotechnics, vol. 2, pp. 1-13.

14. Murata, O., Tateyama, M. and Tatsuoka, F. 1994. Shaking table tests on a large geosyntheticreinforced soil retaining wall model. In Recent Case Histories of Permanent GeosyntheticReinforced Soil Walls (eds F. Tatsuoka and D. Leshchinsky), pp. 287-294. Rotterdam: Balkema.

15. Richardson, G.N. \& Lee, K.L. 1975. Seismic design of reinforced earth walls. Journal of Geotechnical Engineering Division. ASCE, Vol. 103, No. GTI, PP. 1-17.

16. Sakaguchi, M., Muramatsu, M. and Nagura, K. 1992. A discussion on reinforced embankment structures having high earthquake resistance. In: Ochiai, H., Hayashi, S., Otani, J. (Eds.), Proceeding of International Symposium on Earth Reinforcement Practice, ISKyushu'92, Fukuoka, Japan. Balkema, Rotterdam, pp. 287-292.

17. Shinoda, M. \& Bathurst, R. J. 2004. Lateral and axial deformation of PP, HDPE and PET geogrids under tensile load. Geotextiles and Geomembranes, Vol. 22, pp. 205-222.

18. Watanabe, K., Munaf, Y., Koseki, J., Tateyama, M. and Kojima, K. 2003. Behaviors of several types of model retaining walls subjected to irregular excitation, Soils and Foundations, 43(5), 13-27.

19. Woodruff, R. 2003. Centrifuge modelling for MSE-shoring composite walls. M.S. Thesis. University 0

20. Yang, K.-H., Zornberg, J.G., Wright, S.G., and Kniss, K.T. 2007. Numerical modelling of narrow MSE walls with extensible reinforcements. FHWA/TX-08/0-5506-2. 